\title{
Quantification of Mycophenolic Acid and Citrinin Produced by Penicillium sp. Using ${ }^{1}$ H NMR
}

\author{
Angela M. M. P. Valente $\cdot$ Elisangela F. Boffo • \\ Itamar S. Melo • Antonio G. Ferreira
}

Received: 29 October 2013/Published online: 13 February 2014

(C) Springer-Verlag Wien 2014

\begin{abstract}
This study proposes a simple methodology to construct the production curves of mycophenolic acid by Penicillium sp. (CASP5) and citrinin by Penicillium sp. (CATL1.1) in the crude extract, without any purification. The quantification of the compounds was done by ${ }^{1} \mathrm{H}$ nuclear magnetic resonance (NMR) using the signal integration and an internal standard, $N, N$-dimethylformamide. Fungi were cultivated for a period of 20 days and quantification of the metabolites in the extracts was done starting from time zero, 2 days and after this period in an interval of 4 days. The maximum production of mycophenolic acid and citrinin was obtained at 12 and 8 days of fermentation, respectively. These results show that the ${ }^{1} \mathrm{H}$ NMR technique was efficient to define the production curves of mycophenolic acid and citrinin directly in the crude extracts. In addition, the technique made it possible to evaluate the purity degree of the substances obtained in the extraction process. Furthermore, this is the first study that uses the ${ }^{1} \mathrm{H}$ NMR technique to determine the production curves of secondary metabolites.
\end{abstract}

\section{Introduction}

The mycophenolic acid has been reported to possess the following biological properties: antibacterial [1]; antifungal [2]; antiviral and antitumor [3, 4];

\footnotetext{
A. M. M. P. Valente $(\bowtie) \cdot$ A. G. Ferreira

Laboratory of Nuclear Magnetic Resonance, Department of Chemistry, Universidade Federal de São Carlos (UFSCar), Via Washington Luís, Km 235, C.P. 676, São Carlos, SP CEP 13565-905, Brazil e-mail: angvalente@gmail.com

E. F. Boffo

Institute of Chemistry, Universidade Federal da Bahia, Salvador, BA CEP 40170-115, Brazil
}

I. S. Melo

Embrapa Environment, Via SP 340, Km 127,5, C.P. 69, Jaguariúna, SP CEP 13820-000, Brazil 
antipsoriasis [5] and immunosuppressive [6, 7]. However, its immunosuppressive activity was only recognized in 1982 [8] for the prevention and treatment of organ transplant rejection. Recently, it has also been used for the treatment of autoimmune diseases, including systemic lupus erythematosus, lupus membranous nephropathy (LMN), psoriasis and inflammatory eye disease [9-13].

Citrinin is a naturally occurring mycotoxin [14]. When incorporated into animal and human diet, it can cause renal degeneration. It can be found in grains (maize, barley, wheat, rye, rice), fruits (apple, peach, pear), in foodstuffs and biological fluid [15]. Currently, there is great interest in citrinin, because of its antibiotic activity and also as a suitable system to study biosynthetic pathways by isotopic labeling [16-20].

The quantification of secondary metabolites present in the crude extracts produced by fungi is usually performed by sensitive techniques, as the highperformance liquid chromatography [21]. Nuclear magnetic resonance (NMR) is not a technique usually employed for quantification due to its low sensitivity when compared with other techniques. However, it has been attracted much interest because any molecule containing one or more atoms with magnetic moment different than zero can be detected $\left({ }^{1} \mathrm{H},{ }^{13} \mathrm{C},{ }^{15} \mathrm{~N}\right.$ and ${ }^{31} \mathrm{P}$ isotopes, among others). The NMR spectrum contains information about the detected molecule that can be used in identification of metabolite and quantification of substances present in samples proceeding from biological systems. For this reason, NMR is a technique that presents great versatility and it is not destructive, making possible to attain the spectra of whole plants, plant tissues, root cultures, cell suspension and organelles, besides previously purified extracts or metabolites [22].

Another advantage of NMR spectroscopy is the relatively easy and rapid acquisition of data acquisition: a normal ${ }^{1} \mathrm{H}$ NMR spectrum is typically obtained in just a few minutes. It can be also advantageous for quantitative analysis if some technical and instrumental parameters are taken into account. One of the major advantages of quantitative analysis by NMR is, unlike chromatography, the possibility of employing a unique internal standard for all the chemical substances [23].

In this paper, ${ }^{1} \mathrm{H}$ NMR measurements were used for mycophenolic acid and citrinin quantification in fungal extract. The ${ }^{1} \mathrm{H}$ NMR quantitative analysis was performed directly in the biomass produced by Penicillium sp. (CASP5) and Penicillium sp. (CATL1.1) fungi, without any sample manipulation, and the data obtained were used to construct of the metabolite production curve.

\section{Materials and Methods}

\subsection{Materials Collection}

The dry fruits of coffee obtained from Águas da Prata, São Paulo state, Brazil were inoculated in the Environmental Microbiology Laboratory of the EMBRAPA Environment, Jaguariúna-SP. The shelled fruits were sterilized (1 $\mathrm{min}$ in alcohol $70 \%, 4 \mathrm{~min}$ in sodium hypochlorite $2 \%$ and $1 \mathrm{~min}$ in distilled water) and 
inoculated in Petri plates with PDA (Potato, Dextrose and Agar) culture medium. The plates inoculated were incubated at temperature of $25 \pm 1{ }^{\circ} \mathrm{C}$ for 5 days. The fungi were identified by morphological methods, using a field-emission scanning electron microscopy (SEM).

\subsection{Growth of Penicillium sp. and Production of Mycophenolic Acid and Citrinin}

Penicillium sp. (CASP5) and (CATL1.1) were cultivated in flasks (500 mL) with $200 \mathrm{~mL}$ of autoclaved medium during $15 \mathrm{~min}$ at $120{ }^{\circ} \mathrm{C}$. When the medium attained room temperature, fungi inoculation was done using three disks $(0.3 \mathrm{~cm}$ of diameter), which were placed in the incubation room $\left(25^{\circ} \mathrm{C}\right)$ for 8 days in the static mode. Subsequently, the mycelium was separated from filtered liquid medium by common filtration (cotton). The filtered medium was submitted to liquid/liquid extraction with dichloromethane $(2 \times 300 \mathrm{~mL})$ in acid $\mathrm{pH}$. The organic phases were concentrated in a rotary evaporator and analyzed by NMR and mass spectrometry (MS), and the mycophenolic acid and citrinin, respectively, were identified as compounds in larger quantities in the extracts.

After optimization of mycophenolic acid and citrinin extraction and isolation conditions, Penicillium sp. (CASP5) and (CATL1.1) were cultivated for 20 days. The extractions followed the methodology described above and were initiated at zero fermentation time and carried out every $24 \mathrm{~h}$. After 2 days of fermentation for Penicillium sp. (CASP5) and after 4 days of fermentation for Penicillium sp. (CATL1.1) the extractions were carried out every $96 \mathrm{~h}$.

\subsection{NMR Analysis}

For mycophenolic acid and citrinin quantification in extracts using ${ }^{1} \mathrm{H}$ NMR in acid $\mathrm{pH}$, three samples (mass $/ 50 \mathrm{~mL}$ of filtered medium) were taken from each flask and used for every fermentation time (triplicate). The samples were prepared in $1 \mathrm{~mL}$ of deuterated chloroform $\left(\mathrm{CDCl}_{3}\right)$ and increased by $10 \mu \mathrm{L}$ of $N, N$-dimethylformamide $33.33 \%$ aqueous solution, used as an internal standard. TMS (tetramethylsilane) was used as internal reference for chemical shifts $(\delta 0.0)$.

All NMR experiments were performed at $25{ }^{\circ} \mathrm{C}$ on a Bruker DRX400 $9.4 \mathrm{~T}$ spectrometer $\left({ }^{1} \mathrm{H}\right.$ at $\left.400.2 \mathrm{MHz}\right)$ and using a 5 -mm inverse probe with z-gradient. ${ }^{1} \mathrm{H}$ NMR spectra were acquired using $z g$ standard pulse sequence, $64 \mathrm{k}$ data points, pulse widths of $8.5 \mu \mathrm{s}\left(90^{\circ}\right)$, relaxation delay of $1.0 \mathrm{~s}$ and 16 scans. For mycophenolic acid, a spectral width of $4,112 \mathrm{~Hz}$ and an acquisition time of $8.0 \mathrm{~s}$ were used. For citrinin, a spectral width of $7,353 \mathrm{~Hz}$ and acquisition time of $4.5 \mathrm{~s}$ were used.

To accomplish the quantitative measures, an estimation of the longitudinal relaxation time $T_{1}$ for mycophenolic acid, citrinin and DMF was done using the inversion recovery pulse sequence consisting of a $180^{\circ}$ pulse followed by a variable delay $(\tau)$ and a $90^{\circ}$ pulse $(8.5 \mu \mathrm{s})$. Experimentally, the relaxation time was equal to $0.4 \mathrm{~s}$ for the slowest nucleus. 


\subsection{Quantification of Mycophenolic Acid and Citrinin}

The calculation of mycophenolic acid and citrinin concentrations in the extracts $(\mathrm{mg} / \mathrm{mL})$ was made using Eq. (1) [24]

$$
(\text { Compound })=(\mathrm{DMF}) \frac{N_{\mathrm{DMF}} \times A_{\text {compound }}}{N_{\text {compound }} \times A_{\mathrm{DMF}}} \times \mathrm{MM}_{\text {compound }},
$$

where

$(\mathrm{DMF})=\mathrm{DMF}$ concentration $(\mathrm{mol} / \mathrm{mL})$

$N_{\mathrm{DMF}}=\mathrm{DMF}$ hydrogen number in the integral

$A_{\mathrm{DMF}}=\mathrm{DMF}$ hydrogen integral in the ${ }^{1} \mathrm{H}$ NMR spectrum

$N_{\text {compound }}=$ Compound hydrogen number in the integral

$A_{\text {compound }}=$ Compound hydrogen integral in the ${ }^{1} \mathrm{H}$ NMR spectrum

$\mathrm{MM}_{\text {compound }}=\mathrm{mg} / \mathrm{mol}$

\section{Results}

Two colonies, recovered from the isolation plates, were purified on PDA medium and morphologically analyzed by SEM. Both fungi showed phialides, conidiophores and conidia typical of the genus Penicillium (Fig. 1).

NMR results of analysis of these compounds were given as follows:

Mycophenolic acid- ${ }^{1} \mathrm{H}$ NMR- $\delta$ (multiplicity, $J$ in Hz): H-2, 2.38-2.47 (m); H-5, 5.23-5.28 (m); H-6, 3.37 (br d; 6.8); H-7, 1.78 (s); H-1', 5.18 (br s); H-10', 3.74 (s); H-11', 2.13 (s); OH, 7.76 (s); ${ }^{13} \mathrm{C}$ NMR- $\delta$ : C-1, 179.1; C-2, 32.7; C-3, 34.2; C-4, 133.9; C-5, 123.0; C-6, 22.3; C-7, 16.1; C-1', 70.0; C-3', 173.0; C-4', 153.7; C-5', 106.4; C-6', 163.7; C-7', 116.7; C- 8', 144.0; C-9', 122.1; C-10', 61.0; C-11', 11.5.

Citrinin $-{ }^{1} \mathrm{H}$ NMR- $\delta$ (multiplicity, $J$ in Hz): H-1, 8.25 (s); H-3, 4.78 (dq; 6.7; 0.9); H-4, 2.99 (q; 7.2); H-9, 1.35 (d; 6.7); H-10, 1.23 (d; 7.2); H-11, 2.02 (s); H-13, 15.90 (br s); H-14, 15.12 (br s); ${ }^{13} \mathrm{C}$ NMR- $\delta$ : C-1, 162.9; C-3, 81.7; C-4, 34.6; C-4a, 139.1; C-5, 123.1; C-6, 183.4; C-7, 100.3; C-8, 177.2; C-8a, 107.1; C-9, 18.5; C-10, 18.3; C-11, 9.5; C-12, 174.6.

\subsection{Quantification of the Mycophenolic Acid}

For this quantification, the area of the signal of the methylenic hydrogens of mycophenolic acid $(\mathrm{H}-6, \delta 3.37)$ and methylic hydrogens of the DMF $(\mathrm{H}-2, \delta 2.98)$ was measured (Fig. 2b).

Mycophenolic acid concentrations in the extracts of Penicillium sp. (CASP5) were calculated through the ${ }^{1} \mathrm{H}$ NMR spectrum integrals for 2, 4, 8, 12, 16 and 20 days of fermentation. The production curve constructed using these values can be seen in Fig. 3 . 

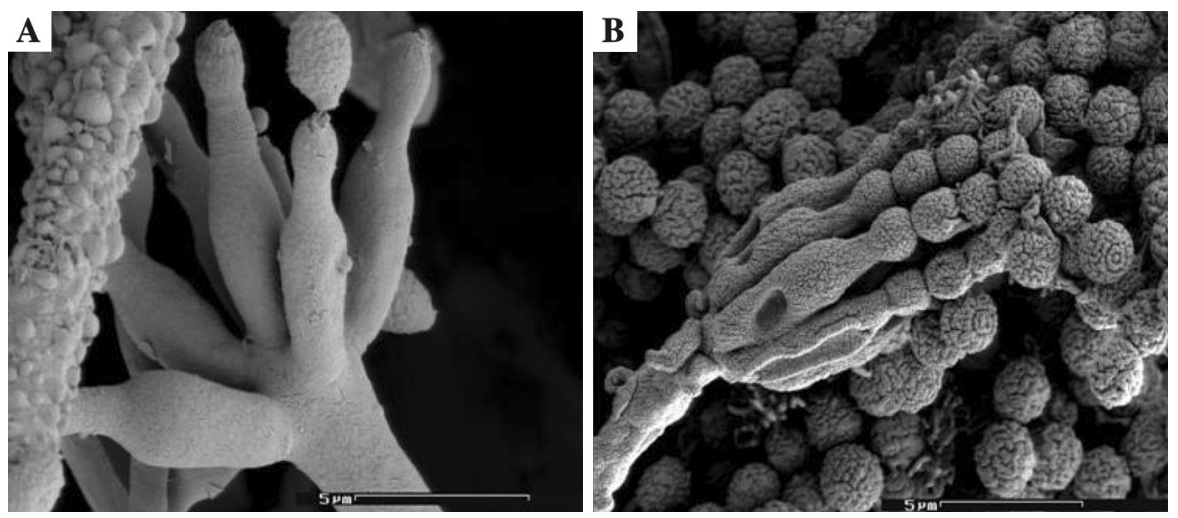

Fig. 1 Scanning electron microscopy (SEM) for a Penicillium sp. (CASP5) and b Penicillium sp. (CATL1.1)

\subsection{Quantification of the Citrinin}

For this quantification, olefinic hydrogen of citrinin $(\mathrm{H}-1, \delta 8.23)$ and aldehyde hydrogen of DMF (H-1, $\delta$ 7.98) were integrated (Fig. 2c).

The quantification of the citrinin in the extract of Penicillium sp. (CATL1.1) was started with 4 days of fermentation, since the citrinin had not been produced with 2 days.

Citrinin concentration in the Penicillium sp. (CATL1.1) extract was calculated through the ${ }^{1} \mathrm{H}$ NMR spectra integrals for 4, 8, 12, 16 and 20 days of fermentation. The production curve, constructed using these values, is shown in Fig. 4.

The purity degree of mycophenolic acid and citrinin was obtained from the ratio between the concentration obtained from the ${ }^{1} \mathrm{H}$ NMR spectra and mass of the extracts produced in $50 \mathrm{~mL}$ of culture filtrate (Table).

Table Concentration of mycophenolic acid and citrinin in $\mathrm{pH} 3$ from Penicillium sp. (CASP5 and CATL1.1), respectively, in 20 days of fermentation

\begin{tabular}{|c|c|c|c|c|c|c|c|}
\hline \multirow[t]{2}{*}{ Sample } & \multirow{2}{*}{$\begin{array}{l}\text { Fermentation } \\
\text { time }\left(27^{\circ} \mathrm{C}\right)\end{array}$} & \multicolumn{3}{|c|}{ Mycophenolic acid } & \multicolumn{3}{|c|}{ Citrinin } \\
\hline & & $\begin{array}{l}{[]^{1} \mathrm{H}} \\
\mathrm{RMN} \\
(\mathrm{mg} / \\
\mathrm{mL})^{*}\end{array}$ & $\begin{array}{l}\text { Mass extract (filtrate/ } \\
50 \mathrm{~mL})(\mathrm{mg})^{*}\end{array}$ & $\begin{array}{l}\% \text { in } \\
\text { extract* }\end{array}$ & $\begin{array}{l}{[]^{1} \mathrm{H}} \\
\mathrm{RMN} \\
(\mathrm{mg} / \\
\mathrm{mL})^{*}\end{array}$ & $\begin{array}{l}\text { Mass extract (filtrate/ } \\
50 \mathrm{~mL})(\mathrm{mg})^{*}\end{array}$ & $\begin{array}{l}\% \text { in } \\
\text { extract } *\end{array}$ \\
\hline 1 & 2 days & 0.40 & 5.70 & 7 & - & - & - \\
\hline 2 & 4 days & 5.72 & 6.11 & 92 & 3.25 & 3.43 & 94 \\
\hline 3 & 8 days & 14.51 & 15.69 & 93 & 11.73 & 12.02 & 98 \\
\hline 4 & 12 days & 18.56 & 19.99 & 92 & 11.57 & 12.09 & 96 \\
\hline 5 & 16 days & 11.15 & 12.03 & 92 & 9.22 & 9.57 & 96 \\
\hline 6 & 20 days & 5.70 & 6.12 & 94 & 6.91 & 7.29 & 95 \\
\hline
\end{tabular}

* Triplicate media 


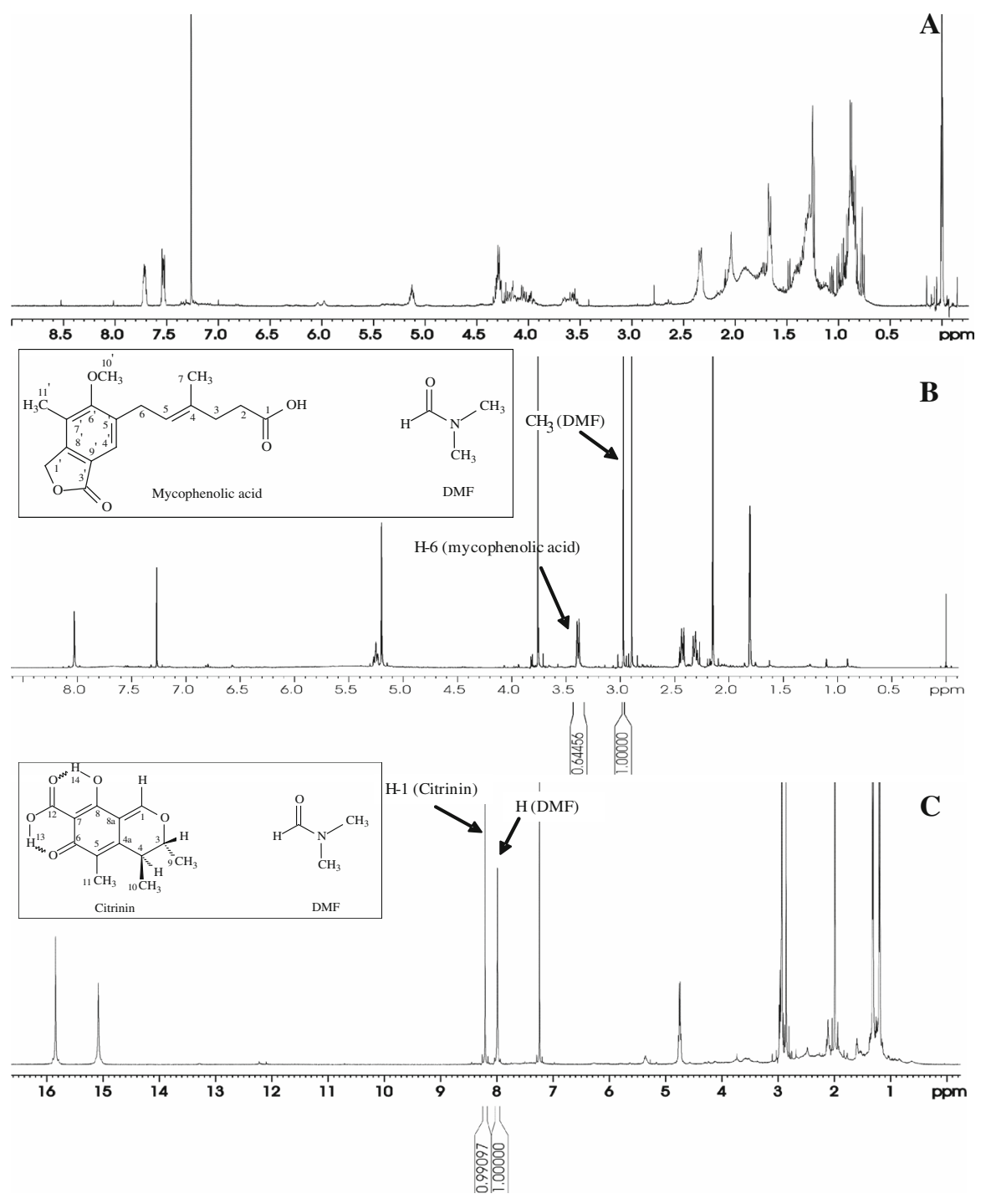

Fig. $2{ }^{1}$ H NMR spectra of a Penicillium sp. (CASP5) extract (pH 3.0) with 0 (zero) fermentation day; b Penicillium sp. (CASP5) extract (pH 3.0) with 8 fermentation days; c Penicillium sp. (CATL1.1) extract (pH 3.0) with 8 fermentation days $\left(400 \mathrm{MHz}\right.$, in $\mathrm{CDCl}_{3}$ )

\section{Discussion}

In the ${ }^{1} \mathrm{H}$ NMR spectra with the zero fermentation time, the signals relating to the compounds of culture medium such as amino acids (yeast extract), $\alpha$ - and $\beta$-glucose (anomeric hydrogens in $\delta 5.15$ and 4.30, respectively) were observed. However, mycophenolic acid and citrinin signals were not observed, because the extraction 


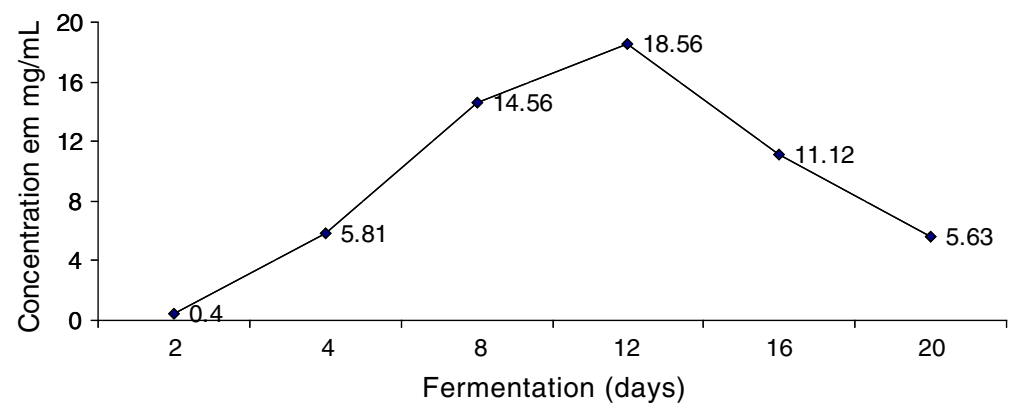

Fig. 3 Production curve of mycophenolic acid by the Penicillium sp. (CASP5)

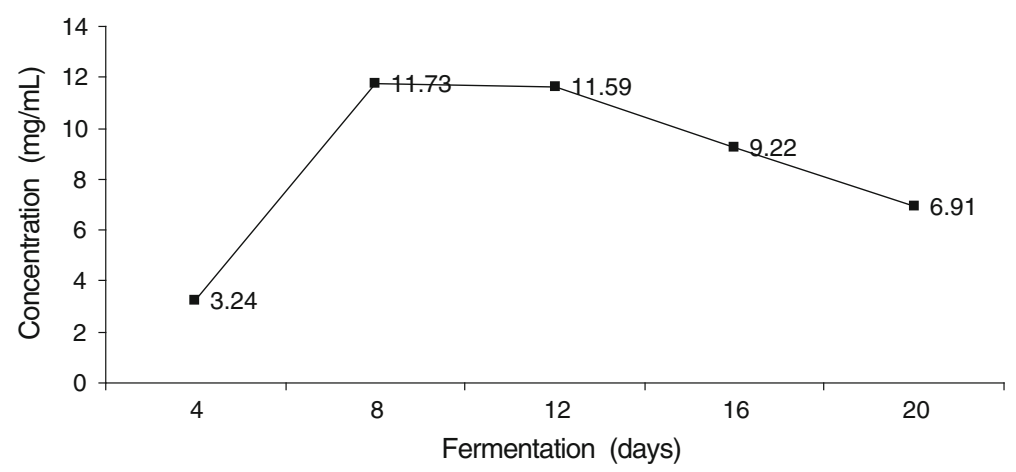

Fig. 4 Production curve of citrinin by the Penicillium sp. (CATL1.1)

was performed after the inoculation of the fungi in the culture medium. Figure 2a shows the ${ }^{1} \mathrm{H}$ NMR spectrum of the extract of Penicillium sp. (CASP5) with zero fermentation time.

\subsection{Quantification of the Mycophenolic Acid}

The quantification of the mycophenolic acid in the Penicillium sp. (CASP5) extract was started with 2 days of fermentation, because signals of this compound in the ${ }^{1} \mathrm{H}$ NMR spectrum have been observed in this period. However, signals of the substances added to the culture medium and yet not metabolized by the fungus were also observed.

In the ${ }^{1} \mathrm{H}$ NMR spectrum with 8 days of fermentation (Fig. 2b), only the mycophenolic acid signals were observed. This result shows that for this period of fermentation, all substances in the culture medium had been metabolized by the fungus.

Analyzing the production of mycophenolic acid in the period from zero to 20 days, it is concluded that the metabolite is synthesized after 2 days of fermentation even without the fungus has completely metabolized the carbon (glucose) and nitrogen (extract yeast) sources present in the culture medium. Thus, 
the production was increasing from 2 to 12 days of fermentation and from this period the fungus began to degrade mycophenolic acid as a carbon source, probably for its survival, due the chemical conditions imposed in the period (Fig. 3).

Analyzing the results, it could be observed that the maximum production of mycophenolic acid occurred on the 12 th day $(18.56 \mathrm{mg}$ in $50 \mathrm{~mL}$ of filtrate, which correspond to $371.2 \mathrm{mg} / \mathrm{L}$ ), and after this period a reduction in metabolite production was observed (Fig. 3). The purity of the mycophenolic acid can be verified in the ${ }^{1} \mathrm{H}$ NMR spectrum.

\subsection{Quantification of the Citrinin}

According to the results obtained for the citrinin, the initial production of the substance was observed after 4 days of fermentation, period in that all carbon and nitrogen sources had already been metabolized. The production curve for citrinin (Fig. 4) shows that the maximum production of this metabolite occurred between 8 and 12 days of fermentation, from this period the production was declined, probably due the chemical conditions of the culture medium.

Citrinin production with 8 days of fermentation was $11.73 \mathrm{mg}$ in $50 \mathrm{~mL}$ of filtrate, which correspond to $234.6 \mathrm{mg} / \mathrm{L}$. Citrinin purity can be verified in the ${ }^{1} \mathrm{H}$ NMR spectrum.

\subsection{Percentage of Mycophenolic and Citrinin in Fungal Extracts}

According to data showed in Table the percentage of mycophenolic acid present in the extract ranged from 92 to $94 \%$, the extract obtained in 2 days of fermentation was not considered.

The percentage of citrinin present in the extract ranged from 94 to $98 \%$. The percentage of the substance in the extract corresponds to the purity degree obtained showing the efficiency of the extraction process.

\section{Conclusion}

The ${ }^{1} \mathrm{H}$ NMR technique has shown to be effective to quantify the mycophenolic acid and citrinin during the fermentation period. The concentrations of the compounds were obtained directly in the spectra of fungal extract without any purification.

In addition, the quantification technique also allowed the calculation of the purity of the substances showing the efficiency of the extraction process.

Acknowledgments We are grateful to CAPES, CNPq, FAPESP and FINEP for financial support.

\section{References}

1. E.P. Abraham, J. Antibiot. 39, 398 (1945)

2. K. Gilliver, Ann. Bot. 10, 271 (1946)

3. K. Ando, S. Suzuki, G. Tamura, K. Arima, J. Antibiot. 21, 649 (1968) 
4. R.H. Williams, D.H. Lively, D.C. Delong, J.C. Line, M.J. Sweeney, G.A. Poore, S.H. Larsen, J. Antibiot. 21, 463 (1968)

5. E.L. Jones, W.W. Epinette, V.C. Hackney, L. Menéndez, P. Frost, J. Invest. Dermatol. 65, 537 (1975)

6. A. Mitsui, S. Suzuki, J. Antibiot. 22, 358 (1969)

7. E.M. Eugui, Transplant Proc. 23, 10 (1991)

8. A.C. Allison, E.M. Eugui, Clin. Transplant. 10, 77 (1996)

9. G. Larkin, S. Lightman, Ophthalm. 106, 370 (1999)

10. T.M. Chan, F.K. Li, C.S. Tang, R.W. Wong, G.X. Fang, Y.L. Ji, N. Eng. J. Med. 343, 1156 (2000)

11. H. Gallagher, P.A. Andrews, Drug Saf. 24, 405 (2001)

12. C.C. Geilen, M. Arnold, C.E. Orfanos, Br. J. Dermatol. 144, 583 (2001)

13. M.Y. Karim, C.N. Pisoni, L. Ferro, M.F. Tungekar, I.C. Abbs, D.P. D'Cruz, M.A. Khamashta, G.R.V. Hughes, Rheum. 44, 1317 (2005)

14. R. Poupko, Z. Luz, R. Destro, J. Phys. Chem. 101, 5097 (1997)

15. B.-J. Xu, X.-Q. Jia, L.-J. Gu, C.-K. Sung, Food Control 17, 271 (2006)

16. J. Barber, J. Staunton, J. Chem. Soc. Chem. Commun. 23, 1098 (1979)

17. J. Barber, J. Staunton, J. Chem. Soc. Perkin Trans. 1, 2244 (1980)

18. J. Barber, R.H. Carter, M.J. Garson, J. Staunton, J. Chem. Soc. Perkin Trans. 1, 2577 (1981)

19. L. Colombo, C. Gennari, D. Potenza, C. Scolastico, J. Chem. Soc. Perkin Trans. 1, 2594 (1981)

20. U. Sankawa, Y. Ebizuka, H. Noguchi, Y. Isikawa, S. Kitaghawa, Y. Yamamoto, T. Kobayashi, Y. litak, Tetrahedron 39, 3583 (1983)

21. A.K. Sadhukhan, R.M.V. Murthy, A.R. Kumar, E.V.S. Mohan, G. Vandana, C. Bhar, K.V. Rao, J. Ind. Microbiol. Biotechnol. 22, 33 (1999)

22. R.G. Ratcliffe, A. Roscher, Y. Sachar-Hill, Prog. Nucl. Magn. Reson. Spectrosc. 39, 267 (2001)

23. A. Caligiani, D. Acquotti, G. Palla, V. Bocchi, Anal. Chim. Acta 585, 110 (2007)

24. D.E. Leyden, R.H. Cox, Analytical applications of NMR, vol. 48 (Wiley-Interscience Publication, New York, 1977), p. 268 